\title{
El Covid-19 en España y sus primeras consecuencias
}

o Covid-19 na Espanha e suas primeiras consequências

La Covid-19 en Espagne: premiers conséquences

The Covid-19 in Spain and its first consequences

\section{Miriam Hermi Zaar and Manuel-Blas García Ávila}

\section{OpenEdition}

\section{Journals}

Electronic version

URL: http://journals.openedition.org/espacoeconomia/10142

DOI: 10.4000/espacoeconomia.10142

ISSN: 2317-7837

\section{Publisher}

Núcleo de Pesquisa Espaço \& Economia

\section{Electronic reference}

Miriam Hermi Zaar and Manuel-Blas García Ávila, « El Covid-19 en España y sus primeras

consecuencias », Espaço e Economia [Online], 17 | 2020, Online since 06 April 2020, connection on 17 June 2020. URL : http://journals.openedition.org/espacoeconomia/10142 ; DOI : https://doi.org/

10.4000/espacoeconomia.10142

This text was automatically generated on 17 June 2020 .

(C) NUPEE 


\title{
El Covid-19 en España y sus primeras consecuencias
}

\author{
O Covid-19 na Espanha e suas primeiras consequências \\ La Covid-19 en Espagne: premiers conséquences \\ The Covid-19 in Spain and its first consequences
}

Miriam Hermi Zaar and Manuel-Blas García Ávila

\section{Introducción}

1 A finales de 2019, China, más específicamente la ciudad de Wuhan, capital de la provincia de Hubei, fue escenario del brote de virus SARS-CoV-2 ${ }^{1}$, responsable de la actual pandemia de la enfermedad Covid-19. Los primeros casos, identificados el 1 de diciembre de 2019, eran de un grupo de trabajadores de un mercado de mariscos de Wuhan en el que tanto las condiciones sanitarias como la presencia de animales salvajes eran cuestionados ${ }^{2}$.

2 La gran capacidad de contaminación y de propagación del Covid-19, hizo que el 11 de marzo de 2020, poco más de tres meses después de detectado el primer caso, esta enfermedad fuera considerada, por la Organización Mundial de la Salud, una pandemia ${ }^{3}$.

3 Este comunicado y el aumento progresivo de los contagios llevó a que, muchos países, apoyados en las recomendaciones de expertos tomasen medidas de contención del Covid-19, asociadas al distanciamiento social, a la suspensión de todas actividades no esenciales y al confinamiento de gran parte de la población. La meta era evitar su propagación.

4 Este artículo tiene como objetivo analizar la evolución del Covid-19 en España y los instrumentos que el gobierno tomó con el propósito de afrontar la crisis provocada por esta pandemia. Para ello consultamos artículos científicos, artículos de la prensa y Webs oficiales que tratan de la propagación de esta enfermedad y de sus consecuencias. 
5 El texto está organizado en cinco apartados. En el primero analizamos la evolución de la enfermedad en el período que comprende desde el inicio del brote a finales de febrero, hasta primeros del mes de abril de 2020. A continuación, examinamos las medidas gubernamentales tomadas en España durante el mes de marzo, con el propósito de afrontar la pandemia. En un tercer apartado tratamos de las primeras consecuencias de esta crisis para España en varios sectores, como el de la salud, la educación, la economía, el trabajo y el medioambiente. A continuación, y teniendo en cuenta que la crisis del Covid-19 en España está completando un mes, elaboramos una evaluación preliminar de los resultados obtenidos a través de las medidas sanitarias y económicas adoptadas, así como de algunas de las contradicciones de esta crisis. Finalizamos poniendo énfasis en las lecciones que podremos aprender de esta crisis.

\section{La evolución del Covid-19 en España}

En España, el primero caso de esta enfermedad se diagnosticó el 31 de enero de 2020 en la Isla de la Gomera, Canarias. Fue el de un turista de nacionalidad alemana ${ }^{4}$. El segundo caso fue confirmado el 10 de febrero en la isla de Palma de Mallorca situada en el archipiélago balear a $2.500 \mathrm{~km}$ de distancia del primer caso. Estos dos casos ya fueron dados de alta.

7 El 24 de febrero el virus saltó a la península, con los primeros casos en las comunidades de Madrid, Cataluña y Valencia, pero fue a partir del 8 de marzo que la enfermedad se descontroló, con la aparición de un gran número de casos en la Comunidad de Madrid.

Desde estas fechas, hasta comienzos de abril, el número de contagiados no paró de crecer en todas comunidades autónomas, pero fundamentalmente en Madrid. En España a pesar de que el número de contagiados es alto, y continúa incrementándose, con un total de 135.032 acumulados el 6 de abril de 2020, se observa una estabilización en los nuevos casos.

$\mathrm{Al}$ acelerado incremento de casos, que en días puntuales alcanzó más de 8.000 e incluso 9.000 infectados, se observa, desde el 31 de marzo, una ralentización de los mismos y una tendencia bajista con una reducción de 7.472, a 7.026, a 6.023 y a 4.273 nuevos casos diarios entre 3 y 6 de abril, demuestra esta tendencia (figura 1 ). 
Figura 1. España. Diagnósticos nuevos por día (entre $2 / 3$ y 6/4/2020)

\section{DIAGNÓSTICOS NUEVOS POR DÍA}

Datos actualizados el 6/04/2020

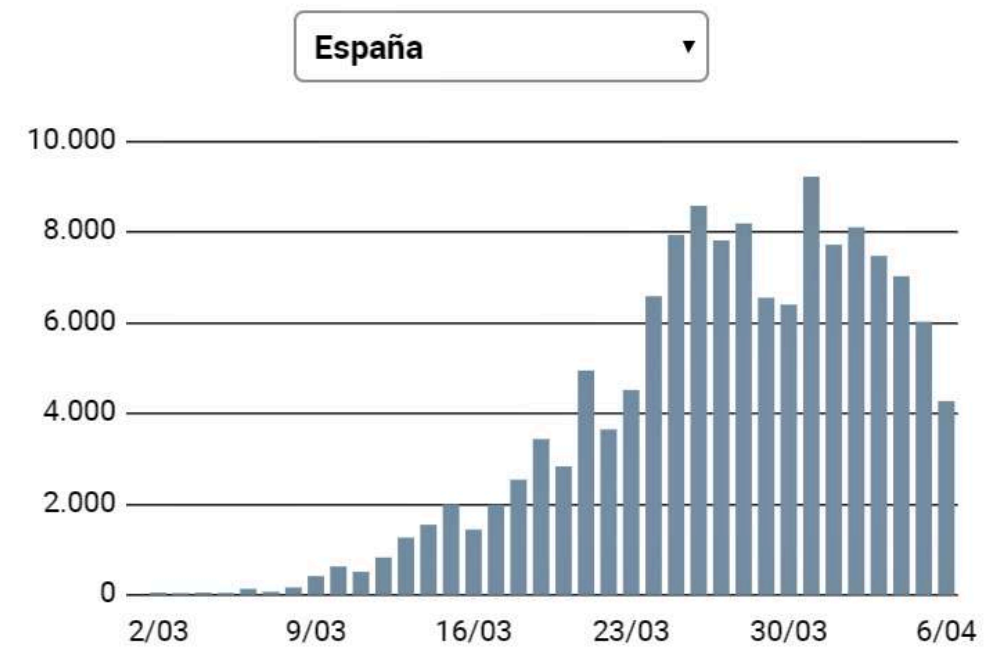

FUENTE: Universidad Johns Hopkins, Protezione Civile (Italia), Santé Publique France y Ministerio de Sanidad (España). ALBERTO HERNÁNDEZ | EL MUNDO GRÁFICOS

Fuente: El Mundo.es < https://www.elmundo.es/ciencia-y-salud/salud/ 2020/03/20/5e74b922fc6c839d588b45db.html>

La distribución geográfica de esta enfermedad destacó, desde el inicio de la crisis, la Comunidad de Madrid, con un total de 38.723 casos hasta el 6 de abril de 2020. La siguen las comunidades de Cataluña con 26.824 casos, Castilla la Mancha con 10.602 casos, Castilla y León con 9.115 casos y País Vasco con 8.810 casos y Andalucía con 8.581 casos (figura 2). 
Figura 2. España. Número total de infectados, muertos y curados por el Covid-19 y número de contagiados por comunidad autónoma

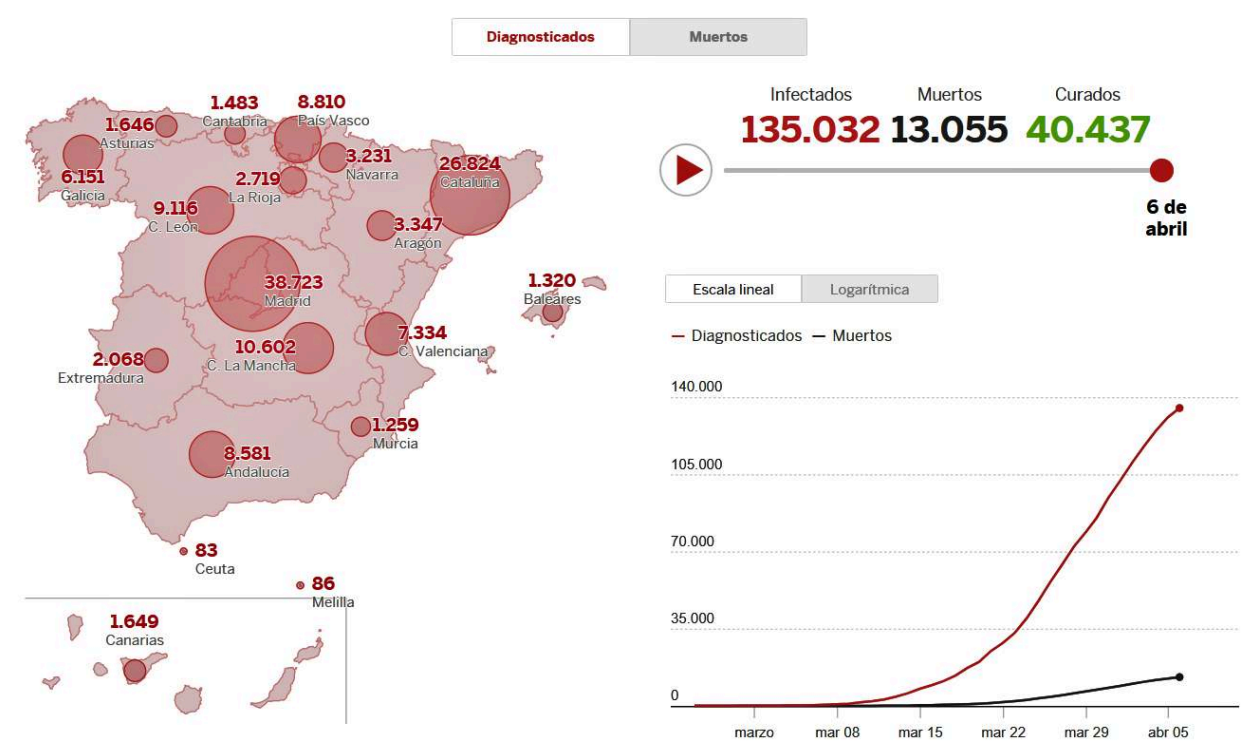

Fuente. El País <https://elpais.com/sociedad/2020/03/30/actualidad/1585589827_546714.html? rel=friso-portada $>$

11 Con relación a las personas fallecidas en España, el primer óbito ocurrió el 13 de febrero en la ciudad de Valencia debido a una neumonía, pero la verdadera causa, el Covid-19, fue diagnosticada solamente veinte días después. En la figura 3 se observa como el número de fallecidos entre los días 19 y 25 de marzo fue ascendiente directo, con crecimientos diarios que oscilaron entre un $67 \%$ y un $11 \%$ sobre el día anterior. En un período posterior, entre los días 26 de marzo y 6 de abril esta tendencia cambió, con un crecimiento diario entre un $17 \%$ y un $17 \%$ negativo, comparando con el día anterior.

12 En esta nueva perspectiva, el número de personas fallecidas disminuyó de 809 a 674 y a 637 entre los días 4 y 5 y 6 de abril. 
Figura 3. Evolución diaria del número de fallecidos (entre 1 de marzo y 6 de abril de 2020)

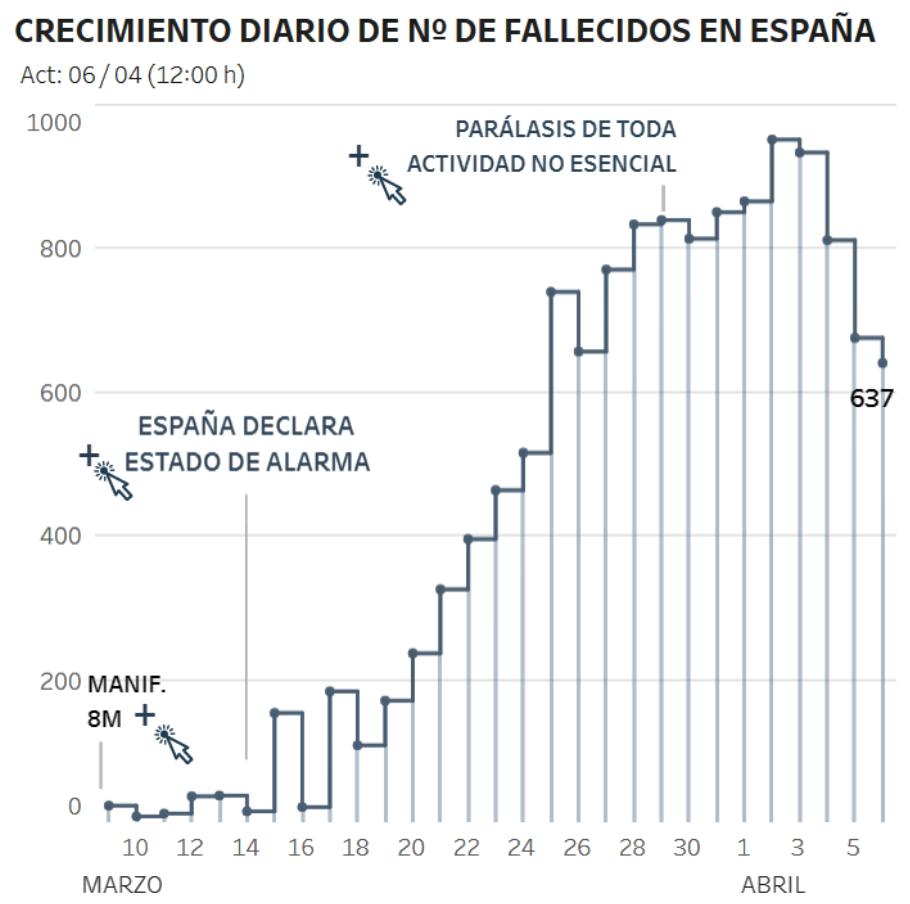

FUENTE: Ministerio de Sanidad JUAN C. SÁNCHEZ | EM GRÁFICOS

Fuente:<https://www.elmundo.es/ciencia-y-salud/salud/ 2020/03/20/5e74b922fc6c839d588b45db.html>

13 En esta circunstancia, los ancianos son los principales afectados. Los datos estadísticos confirman que, en España, el porcentaje de fallecidos es mayor en este grupo de edad, como se observa en la figura 4.

Figura 4. Tasa de mortalidad del Covid-19 hasta 5 de abril de 2020 y su afectación a los ancianos

\section{Muertes}

Última actualización: domingo 5 de abril a las $11.30 \mathrm{~h}$.

Hombres: 4.008 (63.2\%); Mujeres: 2.329 (36.8\%.)

Hombres (\%) Mujeres (\%)

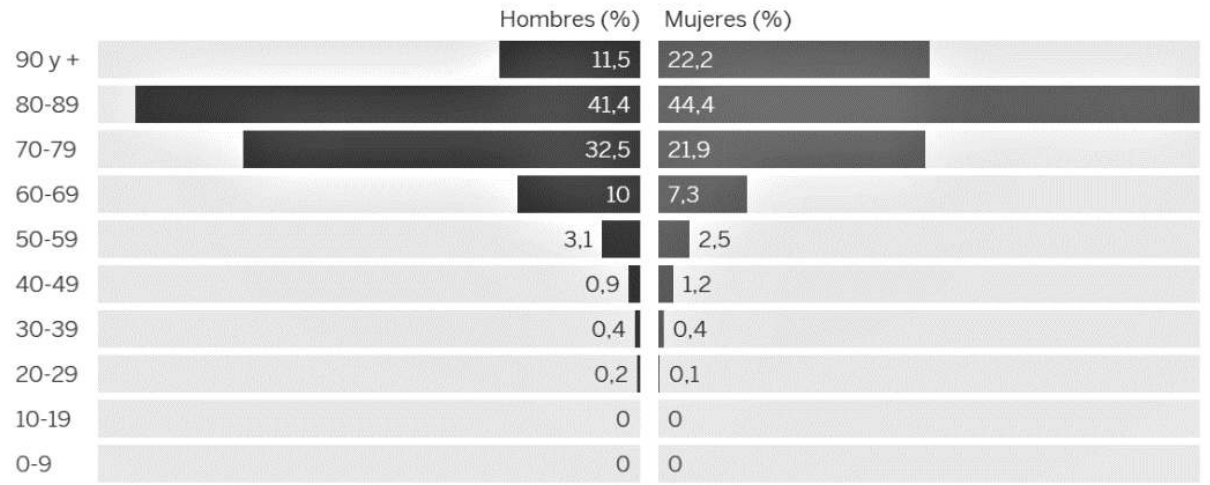

Fuente: El País. https://elpais.com/sociedad/2020/03/30/actualidad/1585589827_546714.html? rel=friso-portada 
La figura 5 presenta una comparación entre la evolución diaria de hospitalizados, recuperados, los que están en la UCI y fallecidos en este primer mes de crisis. Si comparamos, la proporción entre el total de pacientes hospitalizados y de recuperados, observamos que esta ha crecido rápidamente, a favor de los últimos, a partir de la última semana de marzo: el día 25 fue del 7\%, mientras que el 30 de marzo fue del 19\%, el 3 de abril de un $26 \%$ y el 5 de abril del $29 \%$.

Figura 5. Evolución del Covid-19 en España

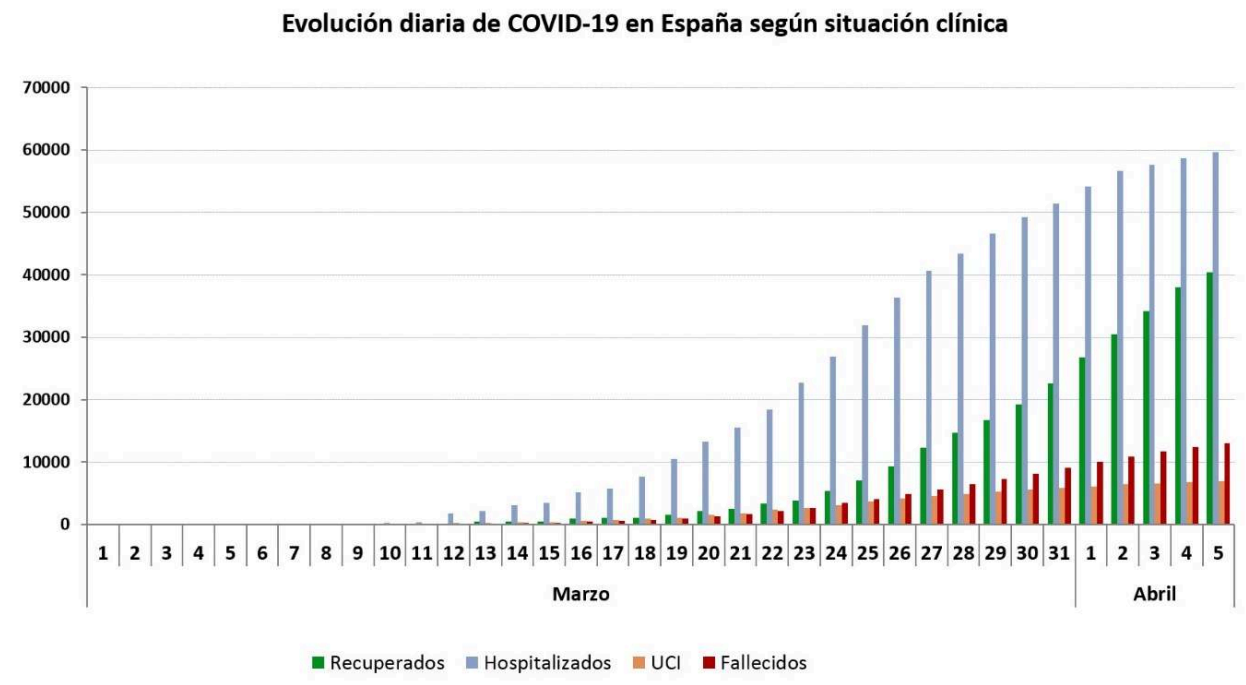

Fuente: RENAVE. ISCIII-CCAES

\section{La actuación del gobierno central español y de las comunidades autonómicas frente a la epidemia}

Debido al inesperado incremento de casos de contagio del Covid-19 en la Comunidad de Madrid y en el País Vasco, el Consejo Interterritorial aprobó el 9 de marzo que España pasase del escenario de "contención" a que estaba sometida desde finales de febrero, a "contención reforzada", lo que implicó la toma de varias medidas adicionales.

Las primeras medidas supusieron para las zonas consideradas de "transmisión alta" (Comunidad de Madrid y las ciudades de Vitoria y de Labastida, en la Comunidad del País Vasco), la suspensión de las actividades docentes presenciales en todos los niveles educativos, desde los cero años hasta el nivel universitario, mientras que, para el conjunto del territorio español, se recomendó en un primer momento evitar los espacios concurridos, en los que no fuera posible mantener la seguridad interpersonal de al menos un metro de distancia. También se pidió que las personas ancianas, que padeciesen de enfermedades crónicas, que limitasen las salidas de su lugar de residencia.

El 13 de marzo, dos días después de que la Organización Mundial de la Salud declarase el Covid-19 como pandemia, y que España registrara un total de 4.209 casos positivos, con 118 fallecimientos y 189 altas, el Consejo de Ministros decretó el "estado de alarma" 
para todo el territorio nacional, previsto en la Constitución en su artículo $116^{5}$ y con duración de dos semanas. A partir de entonces todas las competencias del Estado quedaron en las manos del gobierno central.

18 El objetivo era movilizar todos los medios disponibles para proteger los recursos sanitarios de todo el Estado Español. En este nuevo escenario, bajo la dirección del Presidente del Gobierno, pasaron a ser autoridades competentes delegadas, en sus respectivas áreas de responsabilidad: la Ministra de Defensa, el Ministro del Interior, el Ministro de Transportes, Movilidad y Agenda Urbana y el Ministro de Sanidad.

También se previó que todos los funcionarios, autoridades civiles y trabajadores de las Administraciones Públicas deberían ponerse a disposición del Ministerio de Sanidad, por si fuera necesario adjudicarles "servicios extraordinarios" que tuviesen como objetivo proteger la salud pública frente el coronavirus.

20 A los ciudadanos se les impusieron restricciones de desplazamiento, señalando que solo podrían circular por las vías públicas para la realización de las siguientes actividades:

a) Adquisición de alimentos, productos farmacéuticos y de primera necesidad

b) Asistencia a centros sanitarios

c) Desplazamiento al lugar de trabajo para efectuar su prestación laboral, profesional o empresarial

d) Retorno al lugar de residencia habitual

e) Asistencia y cuidado a mayores, menores, dependientes, personas con discapacidad o personas especialmente vulnerables

f) Desplazamiento a entidades financieras

g) Por causa de fuerza mayor o situación de necesidad

h) Cualquier otra actividad de análoga naturaleza debidamente justificada. ${ }^{6}$

22 A nivel de Unión Europea, se decretó, el 17 de marzo de 2020, por primera vez, el cierre de las fronteras exteriores aéreas y terrestres durante 30 días, una medida que todo indica que fue tomada tardíamente, una vez que en estas fechas Europa ya era considerada el epicentro de la pandemia. El miedo ya había llevado a que, buena parte de los 27 países de la UE, entre ellos España y Alemania, retomasen sus controles fronterizos. Polonia decidió someter a los ciudadanos provenientes de otros Estadosmiembros a confinamiento obligatorio, aunque no presentasen síntomas, y Hungría fue más lejos, impidiendo la entrada de ciudadanos europeos ${ }^{7}$.

23 A finales de marzo, en función del número de contagios y de muertes, que se estaban incrementando diariamente, el gobierno español se vio obligado a decretar la primera prórroga del "estado de alarma" lo que supuso otros 15 días de confinamiento domiciliario, hasta el 11 de abril de 2020.

24 Además, el 31 de marzo, Pedro Sánchez anunció un nuevo paquete de medidas, restringiendo más las actividades económicas, cerrando siderúrgicas, metalúrgicas y actividades del sector de la construcción que continuaban activas. Permanecieron en funcionamiento solamente las actividades esenciales, y sus empleados necesitaron un justificante para poder desplazarse al lugar de trabajo. La ausencia del mismo podría acarrear multas entre 600 y 30.000 euros.

25 El cese de las actividades económicas dio origen a una nueva preocupación, el incremento del desempleo. Según los datos del Ministerio del Trabajo, Migraciones y Seguridad Social publicados el 2 de abril de 2020, en el mes de marzo hubo 302.265 
nuevos demandantes de subsidio de desempleo respecto al mes de febrero, lo que supone un incremento del 9,31\% ${ }^{8}$.

Anticipando estos datos, el gobierno de España publicó un primer decreto de medidas el 17 de marzo de 2020 que tuvo como objetivo agilizar los Expedientes de Regulación de Empleo Temporal (ERTE) ${ }^{9}$, facilitar el cobro de la prestación por desempleo y lanzar avales para garantizar la liquidez de las Pequeñas y Medianas Empresas (Pymes). Para esto movilizó 200.000 millones de Euros (200 billones de Euros según las cifras utilizadas en América), casi el 20\% del PIB español. También aprobó la exoneración del $100 \%$ de las cotizaciones para las Pymes y del $75 \%$ para el resto de empresas, que mantuviesen sus empleados.

Como complemento a las proposiciones anteriores, el 31 de marzo el gobierno español aprobó un nuevo paquete con un centenar de medidas económicas. Se trata de un gran plan de rescate social para los más vulnerables, inquilinos, autónomos y Pymes. Entre estas medidas están:

la creación de una prestación equivalente al 70\% de su base de cotización para las empleadas domésticas dadas de alta en la Seguridad Social que perdieron su trabajo $u$ horas del mismo.

ayuda de 430 euros (en una única parcela) para los trabajadores temporales que no habían llegado a cotizar 12 meses en los últimos seis años y finalizasen un contrato de, al menos, dos meses de duración después del estado de alarma.

una moratoria de seis meses en la cotización a la Seguridad Social para autónomos. Contemplaría tres mensualidades -mayo a julio-, cuyo pago se podría retrasar medio año. También abrió la puerta a aplazar la cuota de abril con un interés del 0,5\%.

la concesión de microcréditos para los inquilinos en situación de vulnerabilidad (parados o afectados por los Expedientes de Regulación Temporal de Empleo, con renta familiar por debajo de los 1.613,5 euros o un alquiler que superase el $35 \%$ de los ingresos).

32 se suspendieron por seis meses los desahucios de las personas vulnerables sin vivienda alternativa y se prorrogaron por medio año los contratos de alquiler que caducasen en los dos meses posteriores a la declaración del estado de alarma del 14 de marzo. se amplió a tres meses la moratoria en las hipotecas de los más damnificados (asalariados y autónomos) $^{10}$.

34 Además, al inicio de abril se está planteando un nuevo paquete de medidas, para los trabajadores más precarios, que no están dados de alta en la Seguridad Social.

\section{Las primeras consecuencias de la crisis del Covid-19 para la sociedad española}

Son y serán muchas las consecuencias que esta crisis ha traído y continuará trayendo a España, así como a un gran número de países. Este análisis comprende los sectores esenciales más afectados con la crisis en el transcurso del mes de marzo de 2020, cuando, bajo una fuerte presión, España vivió una fase muy difícil de la epidemia, con un gran número de contagios y de fallecidos y una lucha desenfrenada para combatirla. 


\section{La crisis en el sistema sanitario y las alternativas para superarla} (UCI), debido al gran número de enfermos (figura 6) y a la falta de equipamiento como respiradores y protección para los sanitarios (batas impermeables, guantes de nitrilo, mascarillas FP2 o FP3, gafas de protección, etc.). La dificultad para conseguir estos equipamientos en estas primeras semanas de la pandemia se debió principalmente a que gran parte de este material sanitario suele ser fabricado en China y que su importación en tiempos de mucha demanda se hace muy complicado.

Figura 6. Evolución diaria acumulada de los hospitalizados en Unidades de Cuidados Intensivos
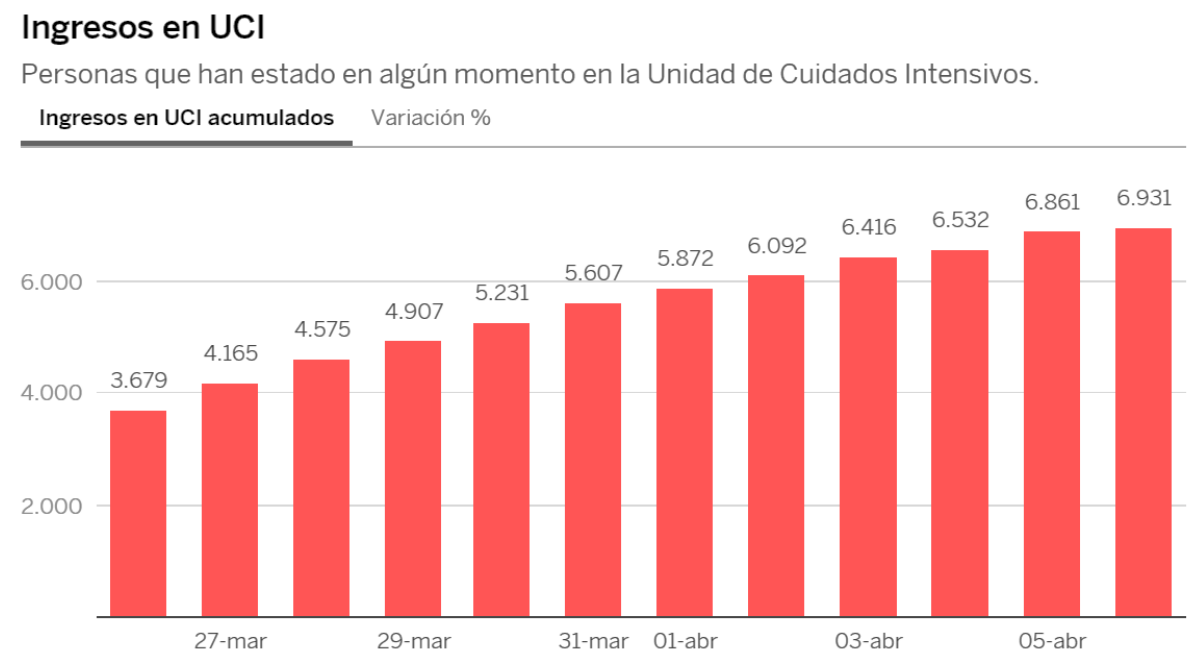

Fuente: < https://elpais.com/sociedad/2020/03/30/actualidad/1585589827_546714.html?rel=frisoportada>

El resultado fue el contagio de muchos profesionales sanitarios. En 22 de marzo este número ascendía a 3.475 profesionales, incrementándose un $177 \%$ en los días siguientes, hasta llegar a los 9.444 el 27 de marzo y ultrapasar los 12.000 el 31 de marzo. Los sanitarios contagiados por el Covid-19 representaban, en esta fecha, un $14 \%$ de todos los infectados en España. Además, a fecha del 6 de abril son doce los sanitarios fallecidos, diez médicos, una enfermera y una técnica en cuidados auxiliares. Un dato que, obviamente, preocupa muchísimo al gobierno español, según Fernando Simón, director del Centro de Coordinación de Emergencias Sanitarias del Ministerio de Sanidad ${ }^{12}$. 

no está permitido salir a la calle acompañado, y solo podemos hacerlo para comprar alimentos, medicamentos o acudir al sistema sanitario. Se solicitó a las personas que presentasen síntomas del Covid-19 que llamasen a urgencias y no salieran de su residencia habitual para no contagiar a otras personas.

46 Además, desde el inicio del "estado de alarma" el gobierno español estimuló a las empresas para que diesen prioridad al trabajo desde casa (teletrabajo) lo que posibilita que madres y padres puedan ejercer su profesión y al mismo tiempo atender a sus hijos y al hogar.

47 Con relación a los estudiantes de todo el territorio español, cuyas actividades presenciales fueron suspendidas el 12 de marzo, se viabilizó la enseñanza a distancia, a través de herramientas informáticas, ordenadores, tables, softwares, etc., con clases y tareas impartidas por sus profesores. Además, Radio Televisión Española (RTVE) incluye una programación especial para los estudiantes -Aprendemos en casa- con varias 
asignaturas en los siguientes horarios: en Clan para alumnos de 6 a 8 años (09:00 a 10:00 horas), de 8 a 10 años (10:00 a 11:00 horas) y de 10 a 12 años (11:00 a 12:00 horas); mientras La2 imparte clases para estudiantes entre los 12 a 14 años (de 12:00 a 13:00 horas) y de 14 a 16 años (de 13:00 a 14:00 horas ${ }^{14}$. Las televisiones españolas, públicas y privadas también realizan una campaña de estímulo para la población, con frases como "Quédate en casa" y "Este virus, lo paramos unidos". Los programas televisivos que hasta esta crisis tenían audiencia presencial, pasan a ser transmitidos desde la casa de sus presentadores. Esta es una forma a más de incentivar a la población para que se queden en sus casas.

49 En estas últimas semanas hemos visto muchas muestras de solidaridad. Un gran número de empresas que colaboran de forma altruista. Mientras algunas donan varios millones de euros para comprar equipamientos, como respiradores artificiales, otras ofrecen suministro o donan materiales para los centros sanitarios como batas sanitarias, sábanas, almohadas, colchones, mantas y otros enseres. Además, varias cadenas de alimentación y entrega de comida preparada, han donado millares de platos preparados y agua embotellada para los profesionales sanitarios y otros colectivos que trabajan en el combate de esta pandemia ${ }^{15}$.

50 También colaboran profesionales, como, por ejemplo, sicólogos que atenden on line y gratuitamente a afectados por la pandemia, y conductores voluntarios de taxis que transportan médicos al domicilio de enfermos.

51 Además de estas, hay un gran número iniciativas que se organizan a través de las redes sociales, como los "voluntarios de Coronavirus Makers" que en las primeras semanas de la crisis fabricaron millares de mascarillas y viseras con 3D y las distribuyeron a los hospitales, o la de jóvenes que se ofrecen a vecinos ancianos para comprarles alimentos y medicinas.

52 Otras iniciativas populares están vinculadas a los artistas que colaboraron en la grabación de la canción Quédate en tu casa y que está disponible en la Web, a los directores de cine y escritores que indican películas y libros y a deportistas que hacen sugerencias sobre ejercicios físicos para que la estancia en casa sea más llevadera.

53 Con el objetivo de garantizar un confinamiento digno a la población más vulnerable el gobierno de Sánchez prohibió el corte de suministros básicos (electricidad, gas, agua y telecomunicaciones) a los hogares vulnerables y aprobó la moratoria del pago de hipotecas sobre la vivienda habitual para trabajadores y autónomos que perdiesen sus empleos o sufriesen una caída drástica en sus ingresos debido a la crisis del Covid-1916. También garantizó el normal funcionamiento de centros de emergencia y acogida a las mujeres en situación de violencia de género que necesiten abandonar su domicilio y a las víctimas de explotación sexual y trata.

\section{Las primeras consecuencias económicas}

54 En la reunión del Consejo Europeo celebrada el 10 de marzo se priorizaron cuatro áreas distintas: 1. La necesidad de contener la propagación de la enfermedad; 2. La garantía de suministro de equipos médicos y productos sanitarios; 3 . La importancia de apoyar y reforzar las investigaciones que busquen encontrar una vacuna; 4. La adopción de un paquete de medidas económicas y fiscales en sectores que sufran una caída de la demanda, apoyando la liquidez de las Pequeñas y Medianas Empresas (Pymes) del sector productivo y protegiendo el empleo ${ }^{17}$. 
55 A pesar de estas y otras medidas, los datos sobre la desaceleración de la economía en función de las medidas de aislamiento y de confinamiento apuntan a una grave recesión durante este año en buena parte de la Eurozona. Goldman Sachs, uno de los mayores grupos de banca de inversión y de valores del mundo, calculó que la Eurozona sufrirá una contracción del $9 \%$ en 2020. A la economía española en particular, para la que se preveía un avance del 1,8\%, la crisis del Covid-19 podrá ocasionar una caída del 9,7\% acompañada de un déficit público de cerca del $10 \%$. También se espera una recuperación para el año 2021, que en la Eurozona podrá ser de un 7,8\% y en España de un $8,5 \%{ }^{18}$.

Con relación a la desaceleración económica, la ruptura de las cadenas de suministros en China en función del estallido de la epidemia, hizo que muchas fábricas españolas y europeas ralentizasen su producción por falta de componentes. La declaración del "estado de alarma" en España solo aceleró un proceso que ya se encontraba en camino, la "hibernación" de los sectores económicos no esenciales.

Ante esta situación, algunas industrias reconvirtieron su producción hacia equipamientos sanitarios con mucha demanda. Así, por ejemplo, la empresa del ramo militar Escribano y las industrias automovilísticas Seat y Renault comenzaron a producir respiradores artificiales, con engranajes, ejes de cajas de cambio y motores adaptados de los limpiaparabrisas de sus vehículos, un proceso que implica cientos de trabajadores. En colaboración con Hersill, la única empresa que fabricaba respiradores pulmonares hasta ahora, estas iniciativas pretenden disponibilizar 5.000 unidades en las próximas semanas.

58 Con el mismo objetivo, Inditex se dispuso a producir batas esterilizadas y organizó el envío desde sus fábricas en China de un avión con 300.000 mascarillas quirúrgicas y 75.000 equipos individuales de protección. Mango donó dos millones de mascarillas y Huawei un millón más ${ }^{19}$. Otras empresas textiles y del calzado españolas procedieron del mismo modo.

A su vez, Repsol se comprometió a producir 3.000 litros por semana de hidroalcohólico (desinfectante) para donar a hospitales y personal sanitario, y empresas de cosméticos (L'Oréal, Roche-Posay y otras) se dispusieron a producir desinfectantes de manos para el mercado y los hospitales.

El desempleo, es otra cuestión delicada. Las últimas cifras revelan cómo el mes de marzo de 2020, principalmente las dos últimas semanas, caracterizadas por la inactividad económica derivada del "estado de alarma", tuvo una repercusión sin precedentes en el aumento de desempleados. A este golpe laboral, no se suman los 620.00 afectados por los Expedientes de Regulación Temporal de Empleo (ERTE) ya que estos empleados siguen vinculados a la empresa recibiendo el $75 \%$ de su salario ${ }^{20}$.

61 Paradójicamente, mientras la economía se encuentra en un período de estagnación y los mercados financieros en una situación de inestabilidad, el medioambiente, se está beneficiando de esta crisis. La reducción de la contaminación atmosférica, especialmente del dióxido de nitrógeno, altamente tóxico, en las regiones más afectadas por el Covid-19, como China, norte de Italia y España ha sido la principal causa. En la figura 7 se puede observar la expresiva reducción de la contaminación en grandes centros urbanos como Madrid y Barcelona. 
Figura 7. Efectos benéficos de la crisis del Covid-19. Contaminación atmosférica en España. Comparación entre marzo de 2019 y marzo de 2020

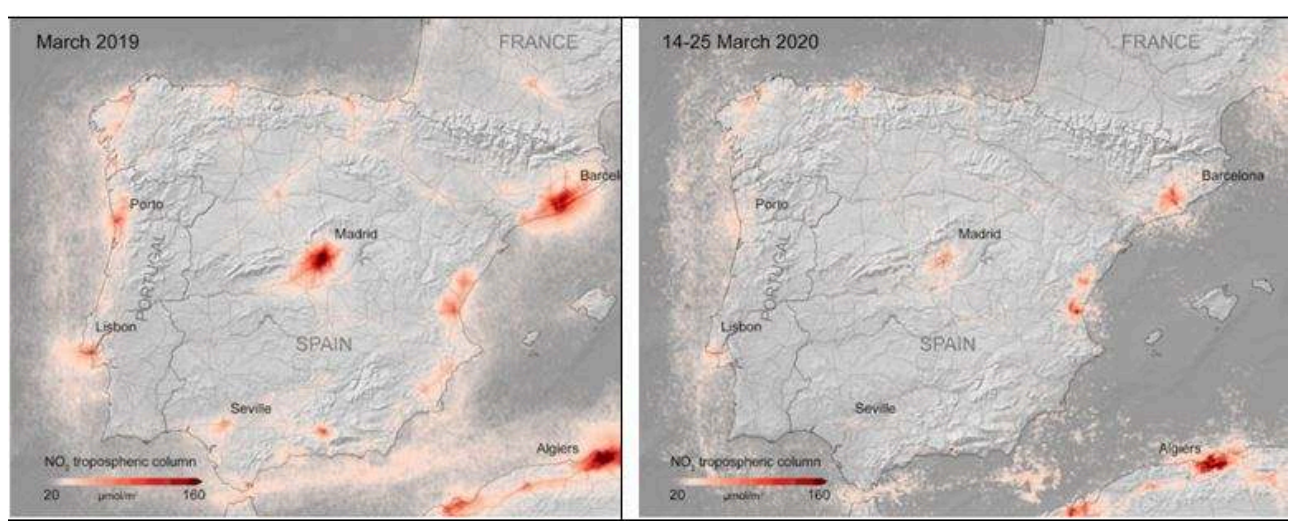

Fuente: National Geographic España. https://www.nationalgeographic.com.es/ciencia/coronavirusreduce-contanimacion-aire-europa_15370

\section{Evaluación preliminar de las medidas gubernamentales y las contradicciones de la crisis}

Estamos ante un proceso que implica una gran dinámica, lo que dificulta su evaluación, aunque sea preliminar. Esto se hizo perceptible durante los días que elaboramos este texto, en los que, tanto la evolución diaria de datos, como las frecuentes medidas del gobierno español, daban mayor complexidad a la coyuntura.

Como evaluación preliminar, podemos afirmar, en primer lugar, que el descenso del número de contagiados y de fallecidos observado en los últimos días, es una demonstración de que las medidas estatales, como el confinamiento y la paralización de las actividades económicas están teniendo un excelente resultado.

También se observa en estos últimos días, una importante mejora de la situación sanitaria española. Esto se debe, por un lado, a la desinfección de hospitales y de las residencias de ancianos, importante foco de la enfermedad; y por otro, a la importación y la producción de millones de mascarillas, guantes y otro material que reforzará el stock en los hospitales, residencias de ancianos y otros sectores con gran demanda.

Otra noticia estimulante es que el Consejo Superior de Investigaciones Científicas (SCIC) está potenciando proyectos de investigación que buscan una vacuna contra el coronavirus SARS-CoV-2. Vários hospitales españoles, entre ellos el Clínico San Carlos, La Paz, Ramón y Cajal, Gregorio Marañón, Príncipe de Asturias y 12 de Octubre, de Madrid, y los hospitales Clínic y Vall d'Hebron de Barcelona, están trabajando para obtener esta vacuna.

Los hospitales madrileños están desarrollando varios ensayos. Entre ellos a) la comprobación de la eficacia y seguridad de Sarilumab en pacientes graves o críticos por Covid-19; b) el estudio sobre la seguridad y la actividad antiviral de Remdesivir en pacientes con infección moderada y grave por coronavirus; c) la investigación de estrategias para intentar prevenir que los profesionales sanitarios que atienden a los pacientes con coronavirus contraigan la enfermedad; d) la evaluación de la eficacia del medicamento con Tocilizumab en pacientes con neumonía por esta enfermedad ${ }^{21}$.

A su vez, el Hospital del Vall d'Hebron logró secuenciar el genoma completo de dos cepas del virus SARS-CoV-2 de dos pacientes, que ya se pueden consultar en GISAID, 
una base de datos internacional, de acceso libre que recoge las secuencias de miles de virus de la gripe y que ahora acoge también las del SARS-CoV-2, así como datos epidemiológicos y clínicos relacionados. lo que facilitará, en un futuro próximo, "el diseño de vacunas y antivirales de acción directa" ${ }^{22}$.

A pesar de estos datos, el 4 de abril, Pedro Sánchez anunció la segunda prórroga del "estado de alarma" y no descarta la posibilidad de que haya otras.

Asimismo, a la espera de que la OMS y el Centro Europeo de Control de Enfermedades elabore un manual que oriente a los gobiernos hacia una vuelta gradual a la normalidad, ya se plantean algunas medidas preliminares, siempre dependiendo de cómo se contenga la pandemia.

70 La vuelta a la vida social tal y como la conocíamos, dependerá de la evolución de la epidemia. Según algunos expertos, estos podrían ser los pasos a seguir:

71 Poder salir a la calle en solitario o con niños (lo que hoy está restringido y prohibido, respectivamente), lo que permitiría caminar y hacer ejercicios al aire libre, cerca de los domicilios, aunque siempre asegurando un distanciamiento social. Es probable que las personas mayores o con ciertas patologías tengan que prolongar su confinamiento más que las jóvenes y sanas.

Disfrutar de ambientes de ocio al aire libre, incluida la playa, siempre que no se masifique.

Reducción de los aforos en los establecimientos de restauración y la adopción de medidas de higiene máximas.

Reducción de los aforos de eventos como conciertos, festivales, competiciones deportivas, mayor control del distanciamiento y medidas de higiene.

Sin embargo, la vuelta a las aulas representa un punto de inflexión, ya que las aglomeraciones deben ser evitadas.

La vuelta a las actividades económicas dependerá de las medidas que el gobierno adopte, pero en un principio podrían ser estas:

Retomar el 11 de abril las actividades no esenciales suspendidas el 30 de marzo, como construcción civil, siderúrgicas o metalúrgicas.

78 Aunque es conveniente que el teletrabajo se alargue más allá del fin del confinamiento en los casos en los que sea posible, es importante que se permita la vuelta al trabajo de los más jóvenes y de aquellos que ya están inmunizados.

79 Expedir un "salvoconducto sanitario" para que las personas que hayan pasado la enfermedad y, supuestamente, estén inmunizados, puedan incorporarse antes a una vida normal, tras pasar un test de anticuerpos ${ }^{23}$.

A pesar de este contexto en el que se vislumbra la vuelta a la normalidad, pensamos que sería oportuno cuestionar algunos aspectos de la gestión de esta crisis:

81 Creemos que el primer punto a señalar, porque contribuyó decisivamente a la propagación del Covid-19 en toda Europa, fue la tardanza con la que la Organización Mundial de la Salud declaró el Covid-19 como pandemia. Esto retrasó la toma de medidas por parte de los gobiernos de los Estados-miembros e, inicialmente provocó que los países más afectados tuviesen que tomar medidas en solitario, lo que retrasó a la contención de la enfermedad a nivel europeo. 

de equipamientos sanitarios y la ausencia de reservas suficientes para una emergencia como esta. Un impasse que solo se está consiguiendo resolver dos semanas después del inicio del "estado de alarma" con la reconversión de algunas industrias, la organización de hospitales de campaña y la importación de materiales sanitarios. Esta coyuntura trajo como resultado un colapso en los hospitales públicos, principalmente en la Comunidad de Madrid y provocó el contagio de miles de profesionales de la salud y la muerte de varios de ellos, en el período analizado.

Una tercera cuestión que queremos poner sobre la mesa es si las medidas adoptadas para contener el avance de la epidemia están siendo suficientes. George Gao, director general de los Centros de Control y Prevención de Enfermedades (CDC) de China, que participó en el aislamiento e identificación del virus y en los primeros estudios que detallaron la epidemiología de la enfermedad, en una entrevista a Sciencemag.org se refirió así al mayor error de Europa:

"The big mistake in the U.S. and Europe, in my opinion, is that people aren't wearing masks. This virus is transmitted by droplets and close contact. Droplets play a very important role-you've got to wear a mask, because when you speak, there are always droplets coming out of your mouth. Many people have asymptomatic or presymptomatic infections. If they are wearing face masks, it can prevent droplets that carry the virus from escaping and infecting others." ${ }^{24}$

Sobre esta medida, hasta el 3 de abril había diferentes opiniones. Mientras los expertos chinos defienden la obligatoriedad del uso de mascarillas, otras organizaciones como la Organización Mundial de la Salud desaconsejaban su utilización para las personas sanas ${ }^{25}$. Solamente hoy, 3 de abril de 2020, cuando más de un millón de personas está sufriendo las consecuencias de esta pandemia, la OMS recomienda el uso generalizado de mascarillas.

En España, en este nuevo contexto y la vuelta gradual a la normalidad, para la que el uso de mascarillas debería ser imprescindible, está generando un intenso debate sobre el que no existe consenso. La posición que está ganando más fuerza es la de recomendar su uso en espacios públicos ante la posibilidad que personas contagiadas por el SARSCov-2 transmitan el virus, aunque no presenten síntomas.

Finalmente es importante resaltar que, aunque el porcentaje del número de infectados está estabilizándose, la incógnita sobre el fin de los contagios es grande (de más de 1.250.000 contagiados en el mundo a la fecha 6 de abril de 2020, 135.000 son españoles), pero, como mencionamos anteriormente, de modo gradual volveremos a la normalidad, ya que la presión de los empresarios para que las actividades se restablezcan es muy grande.

87 Entonces, ¿qué pasará con la seguridad sanitaria ciudadana? ¿Estaremos preparados para la vuelta a la normalidad? Es fundamental que se piense en medidas e instrumentos que protejan los ciudadanos y controlen esta pandemia lo más rápido posible.

\section{Lo que aprendemos con el Covid-19}

Esta crisis, definida por la ONU como la mayor desde la Segunda Guerra Mundial, ya está poniendo en cuestión el actual modelo económico, basado en "la 
desregularización, la privatización y el abandono por el Estado de muchas áreas de la provisión social" ${ }^{26}$, en detrimento del estado de bienestar. marcha acciones hacia sociedades más resilientes, condición sine qua non para que éstas se vean menos afectadas en los períodos de dificultades económicas, sanitarias o de cualquier otra índole. Solo así estaremos preparados para las crisis, que previsiblemente seguiremos padeciendo en el futuro.

\section{BIBLIOGRAPHY}

BOLETÍN OFICIAL DEL ESTADO. LEY Orgánica 4/1981, de 1 de junio, de los estados de alarma, excepción y sitio. <https://www.boe.es/eli/es/lo/1981/06/01/4/con>.

BOLETÍN OFICIAL DEL ESTADO. Real Decreto 463/2020, de 14 de marzo, por el que se declara el estado de alarma para la gestión de la situación de crisis sanitaria ocasionada por el COVID-19 <https://www.boe.es/boe/dias/2020/03/14/pdfs/BOE-A-2020-3692.pdf>. 
EL INDEPENDENTE, 30/03/2020. Seat empieza a producir en Martorell respiradores asistidos con el motor adaptado de limpiaparabrisas <https://www.elindependiente.com/economia/ 2020/03/30/seat-empieza-a-producir-en-martorell-respiradores-asistidos-con-el-motoradaptado-de-limpiaparabrisas/>.

EL PAÍS, 31/01/2020. Sanidad confirma el La Gomera el primer caso de coronavirus en España <https://elpais.com/sociedad/2020/01/31/actualidad/1580509404_469734.html>.

EL PAÍs, 17/03/2020. Sánchez anuncia un plan que movilizará 200.000 millones para amortiguar el impacto de la crisis del coronavirus <https://elpais.com/economia/2020-03-17/el-gobiernoaprobara-una-moratoria-para-el-pago-de-hipotecas.html>.

EL PAÍs, 23/03/2020. Así son los nuevos test rápidos para detectar el coronavirus <https:// elpais.com/sociedad/2020-03-23/tres-tipos-de-test-para-detectar-el-coronavirus.html>.

EL PAÍS, 24/03/2020. La economía española se desplomará un 10\% este año, según Goldman Sachs y el IESE <https://elpais.com/economia/2020-03-24/la-economia-espanola-se-desplomara-un-10este-ano-segun-goldman-sachs-y-el-iese.html>.

EL PAÍs, 31/03/2020. El Gobierno aprueba un plan social para los más vulnerables y ayudas para inquilinos, autónomos y pymes <https://elpais.com/economia/2020-03-31/el-gobierno-apruebaayudas-extraordinarias-para-empleadas-de-hogar-y-temporales.html>.

EL PAÍS, 31/03/2020. El presidente de Lombardía: "Intentaron estafarnos al comprar material. Está lleno de bandidos" <https://elpais.com/sociedad/2020-03-30/el-presidente-de-lombardiaintentaron-estafarnos-al-comprar-material-esta-lleno-de-bandidos.html>.

EL PAÍS, 01/04/2020. La crisis del coronavirus. <https://elpais.com/sociedad/2020/03/30/ actualidad/1585589827_546714.html?rel=friso-portada>.

EL PAÍS, 01/04/2020. Cataluña avala limitar la ventilación mecánica a mayores de 80 años en las emergencias médicas <https://elpais.com/sociedad/2020-04-01/cataluna-recomienda-limitar-laventilacion-mecanica-a-mayores-de-80-anos.html>.

EL MUNDO.ES, 20/03/2020. Crecimiento diario del número de fallecidos en España. <https:// www.elmundo.es/ciencia-y-salud/salud/2020/03/20/5e74b922fc6c839d588b45db.html>.

EXPANSIÓN.COM, 28/03/2020. <https://www.expansion.com/empresas/ 2020/03/28/5e7f09d0468aeb2a778b45da.html>.

HARVEY, David. Breve historia del neoliberalismo. Madrid: Ediciones Akal, 2007.

HUI, D.S. et al. The continuing 2019-nCoV epidemic threat of novel coronaviruses to global health - The latest 2019 novel coronavirus outbreak in Wuhan, China. International Journal of Infectious Diseases 91, 2020, p. 264-266 <https://www.ijidonline.com/article/S1201-9712(20)30011-4/pdf>.

INSTITUTO DE SALUD CARLOS III. Situación del Covid-19 en España. <https://covid19.isciii.es/>.

GACETA MÉDICA. La UE hace frente común para mitigar las consecuencias del coronavirus $<$ https://gacetamedica.com/politica/la-ue-hace-frente-comun-para-mitigar-las-consecuenciassanitarias-y-economicas-del-coronavirus/>.

LA VANGUARDIA, 31/03/2020. Logran secuenciar genoma del virus SARS-CoV-2 en dos pacientes en Barcelona <https://www.lavanguardia.com/vida/20200331/48222117132/logran-secuenciargenoma-sars-cov-2-vall-hebron-barcelona.html>.

MINISTERIO DEL TRABAJO, MIGRACIONES Y SEGURIDAD SOCIAL. El paro registrado aumenta en 302.365 personas en marzo respecto al mes anterior <http://prensa.empleo.gob.es/WebPrensa/ noticias/laboral/detalle/3768 >. 
ORGANIZACIÓN MUNDIAL DE LA SALUD, 12/01/2020. <https://www.who.int/csr/don/12january-2020-novel-coronavirus-china/es/>

ORGANIZACIÓN MUNDIAL DE LA SALUD, 11/3/2020. <https://www.who.int/dg/speeches/detail/ who-director-general-s-opening-remarks-at-the-media-briefing-on-covid-19---11-march-2020>.

ORGANIZACIÓN MUNDIAL DE LA SALUD. Consejos para la población sobre el nuevo coronavirus (2019-nCoV): cuándo y cómo usar mascarilla <https://www.who.int/es/emergencies/diseases/ novel-coronavirus-2019/advice-for-public/when-and-how-to-use-masks>.

REDACCIÓN MÉDICA. Coronavirus: España tiene 9.444 sanitarios infectados, un 75\% más en 3 días. <https://www.redaccionmedica.com/secciones/sanidad-hoy/coronavirus-espana-tiene-9-444sanitarios-infectados-un-75-mas-en-3-dias-7049>.

RADIO TELEVISIÓN ESPAÑOLA (RTVE) 20/03/2020. <https://www.rtve.es/rtve/20200320/rtveaprendemos-casa/2010489.shtml>.

SCIENCEMAG.ORG. Not wearing masks to protect against coronavirus is a 'big mistake,' top Chinese scientist says <https://www.sciencemag.org/news/2020/03/not-wearing-masks-protectagainst-coronavirus-big-mistake-top-chinese-scientist-says>.

ZAAR, Miriam-Hermi. Gentrificación y turismo urbano. ¿Cómo se articulan? Ar@cne. Revista Electrónica de Recursos de Internet sobre Geografía y Ciencias Sociales. Barcelona: Universidad de Barcelona, no 230, 1 de febrero de 2019 <http://www.ub.edu/geocrit/aracne/aracne-230.pdf >.

\section{NOTES}

1. D. S. Hui et al, $2020<\mathrm{https}$ //www.ijidonline.com/article/S1201-9712(20)30011-4/pdf>.

2. OMS, 12/1/2020 < https://www.who.int/csr/don/12-january-2020-novel-coronavirus-china/ es/>

3. OMS, 11/3/2020. <https://www.who.int/dg/speeches/detail/who-director-general-s-openingremarks-at-the-media-briefing-on-covid-19---11-march-2020>.

4. El País, 31/01/2020 < https://elpais.com/sociedad/2020/01/31/actualidad/ 1580509404_469734.html>.

5. Reforzada por la ley Orgánica 4/1981 que establece lo siguiente en su artículo primero que: "Procederá la declaración de los estados de alarma, excepción o sitio cuando circunstancias extraordinarias hiciesen imposible el mantenimiento de la normalidad mediante los poderes ordinarios de las Autoridades competentes". <https://www.boe.es/eli/es/lo/1981/06/01/4/con>.

6. Boletín Oficial del Estado, de 14 de marzo de $2020<\mathrm{https}$ //www.boe.es/boe/dias/2020/03/14/ pdfs/BOE-A-2020-3692.pdf>.

7. El País < https://elpais.com/sociedad/2020-03-17/europa-se-blinda-hacia-fuera-y-seresquebraja-por-dentro.html>.

8. Ministerio del Trabajo, Migraciones y Seguridad Social. < http://prensa.empleo.gob.es/ WebPrensa/noticias/laboral/detalle/3768 >.

9. Se trata de una autorización que reciben las empresas para puedan suspender temporalmente los contratos de trabajo.

10. El País < https://elpais.com/economia/2020-03-31/el-gobierno-aprueba-ayudasextraordinarias-para-empleadas-de-hogar-y-temporales.html>.

11. Cadena Ser < https://cadenaser.com/ser/2020/04/02/sociedad/1585807186_528625.html>. Este número puede ser mayor.

12. Redacción Medica <https://www.redaccionmedica.com/secciones/sanidad-hoy/coronavirusespana-tiene-9-444-sanitarios-infectados-un-75-mas-en-3-dias-7049>. 
13. El País < https://elpais.com/sociedad/2020-03-23/tres-tipos-de-test-para-detectar-elcoronavirus.html>, <https://elpais.com/sociedad/2020-03-30/el-presidente-de-lombardiaintentaron-estafarnos-al-comprar-material-esta-lleno-de-bandidos.html>.

14. RTVE < https://www.rtve.es/rtve/20200320/rtve-aprendemos-casa/2010489.shtml>. Las clases quedan disponibles en las Webs de los canales.

15. Expansión < https://www.expansion.com/empresas/ 2020/03/28/5e7f09d0468aeb2a778b45da.html>

16. El País <https://elpais.com/economia/2020-03-17/el-gobierno-aprobara-una-moratoria-parael-pago-de-hipotecas.html>.

17. Gaceta Médica <https://gacetamedica.com/politica/la-ue-hace-frente-comun-para-mitigarlas-consecuencias-sanitarias-y-economicas-del-coronavirus/>.

18. El País < https://elpais.com/economia/2020-03-24/la-economia-espanola-se-desplomaraun-10-este-ano-segun-goldman-sachs-y-el-iese.html>.

19. El Independente <https://www.elindependiente.com/economia/2020/03/30/seat-empieza-aproducir-en-martorell-respiradores-asistidos-con-el-motor-adaptado-de-limpiaparabrisas/>.

20. Ministerio del Trabajo, Migraciones y Seguridad Social. El paro registrado aumenta en 302.365 personas en marzo respecto al mes anterior <http://prensa.empleo.gob.es/WebPrensa/noticias/ laboral/detalle/3768 >

21. La Vanguardia. https://www.lavanguardia.com/local/madrid/20200331/48209530866/8hospitales-de-madrid-investigan-tratamientos-de-covid-19-y-se-pide-permiso-para-otros-6ensayos-clinicos.html

22. La Vanguardia. < https://www.lavanguardia.com/vida/20200331/48222117132/logransecuenciar-genoma-sars-cov-2-vall-hebron-barcelona.html>.

23. El País, 05/04/2020. https://elpais.com/sociedad/2020-04-04/los-primeros-pasos-tras-elconfinamiento-asi-volveremos-a-la-vida-normal.html

24. Sciencemag.org < https://www.sciencemag.org/news/2020/03/not-wearing-masks-protectagainst-coronavirus-big-mistake-top-chinese-scientist-says>. Traducción de la autora: "El gran error en Estados Unidos y Europa, en mi opinión, es que las personas no usan mascarillas. Este virus se transmite por gotitas y contacto cercano. Las gotas juegan un papel muy importante: tienes que usar una mascarilla, porque cuando hablas, siempre salen gotas de tu boca. Muchas personas tienen infecciones asintomáticas o presintomáticas. Si usan máscaras faciales, pueden evitar que las gotas que transportan el virus escapen e infecten a otros."

25. OMS < https://www.who.int/es/emergencies/diseases/novel-coronavirus-2019/advice-forpublic/when-and-how-to-use-masks>.

26. David Harvey, 2007, p. 9.

27. Miriam Zaar, 2019 <http://www.ub.edu/geocrit/aracne/aracne-230.pdf >.

\section{ABSTRACTS}

Covid-19 is being responsible for several tens of thousands of deaths worldwide. Furthermore, it is causing a major economic slowdown, which may lead to a global crisis. The objective of this article is to evaluate how this process is developing in Spain from the health, economic, social and labor fields. For this, the evolution of the disease is linked to the actions of the Spanish government to combat it. The analyzed period is approximately 30 days, and includes from the 
beginning of the outbreak of the virus in Spain at the end of February, until the beginning of April 2020.

El Covid-19 está siendo el responsable de varias decenas de miles de muertos en todo el mundo. Además, está provocando una importante desaceleración económica, que podrá llevar a una crisis mundial. El objetivo de este artículo es evaluar como este proceso está desarrollándose en España desde el ámbito sanitario, económico, social y laboral. Para esto se vincula la evolución de la enfermedad a las acciones del gobierno español para combatirlo. El período analizado es de aproximadamente de 30 días, y comprende desde el inicio del brote del virus en España a finales del mes de febrero, hasta principios de abril de 2020.

O Covid-19 está sendo o responsável por várias dezenas de milhares de mortos em todo o mundo. Além disso, está causando uma grande desaceleração econômica, que poderá levar a uma crise mundial. o objetivo deste artigo é avaliar, dos pontos de vista sanitário, econômico, social e do trabalho, como esse processo está se desenvolvendo na Espanha. Para isto, procurou-se vincular a evolução da doença às ações do governo espanhol para combatê-la. O período analisado é de aproximadamente 30 dias e inclui desde o início da eclosão do vírus na Espanha, no final de fevereiro, até o início de abril de 2020.

La Covid-19 est responsable de la mort de milliers de personnes autour du monde, ainsi qu'il entraîne un freinage économique dont le résultat peut être une crise mondiale. Cet article veut montrer l'impact du virus et ses conséquences en Espagne. Pour cela, on associe l'évolution de la maladie aux actions gouvernementales entre la fin de février et le début d'avril 2020, dont les résultats sont encore inconnus.

\section{INDEX}

Palavras-chave: Covid-19; Espanha; medidas aprovadas pelo governo espanhol; Covid-19 e suas consequências à saúde, econômicas e trabalhistas.

Mots-clés: Covid-19, Espagne, effets sanitaires, économiques, sociales et ouvrières, crise, capitalisme.

Palabras claves: Covid-19; España; medidas aprobadas por el gobierno español; el Covid-19 y sus consecuencias sanitarias, económicas y laborales.

Keywords: Covid-19; Spain; Covid-19 and its health, economic and labor consequences.

\section{AUTHORS}

\section{MIRIAM HERMI ZAAR}

Universidad de Barcelona

miriamzaar@gmail.com

MANUEL-BLAS GARCÍA ÁVILA

Investigador independiente

manuelblasg@gmail.com 